\section{Sociologia aplicada}

Gláucia VILLA-BÔAS. Mudança provocada: passado e futuro no pensamento sociológico brasileiro. Rio de Janeiro, FGV, 2006. 180 páginas.

\section{Luiz Carlos Jackson}

Desde os anos de 1980, especialmente a partir do livro A universidade da comunhão paulista, de Irene Cardoso, constitui-se uma área específica de estudos sociológicos que tem como objeto a história das ciências sociais no Brasil. Tal movimento relaciona-se a mudanças - sobretudo a expansão da pós-graduação por todo o país ocorridas no campo dessas disciplinas, desde os anos de 1970, que implicaram uma especialização mais estrita.

Embora houvesse uma diferenciação temática ou teórica desde a década de 1940, quase toda produção acadêmica até o final dos anos de 1960 focalizava o problema da modernização brasileira. A análise das mudanças ou das possibilidades (e entraves) de reforma da sociedade brasileira era direção quase obrigatória a todas as linhas de pesquisa consagradas no período. Variavam as perspectivas analíticas, mas o objeto era de certo modo o mesmo para todos e, por isso, a comunidade relativamente restrita de cientistas sociais dialogava entre si, diferentemente do que ocorreria a partir de então, quando a especialização progressiva levaria à dispersão temática e à formação de grupos, definidos por áreas de pesquisa.

Nesse novo cenário, polarizaram-se os estudos sobre a história das ciências sociais no Brasil em torno de duas perspectivas típicas: uma que retém em boa parte a dimensão política que a aproxima do período anterior, dos debates sobre o desenvolvimento brasileiro e de uma história das idéias; outra que insiste na reconstrução estritamente sociológica do campo acadêmico, visando a constituir uma sociologia dos intelectuais. A primeira orientação tem como preocupação principal a análise de textos, contextualizados em função das interpretações (e das opções metodológicas) sugeridas sobre os processos sociais estudados e das configurações históricas abrangentes a partir das quais se constituiriam. Enfatiza-se, na segunda, a reconstrução sociológica dos meios específicos (e de suas relações com os centros decisórios e agências de fomento), nos quais a atividade intelectual se realiza em meio às disputas motivadas pelas possibilidades de acesso e controle das posições dominantes do campo de atividades estudado.

Mudança provocada, de Glaucia Villas Bôas, professora de sociologia da UFRJ, inscrevese com muita competência na primeira dessas vertentes analíticas, incorporando também a segunda, sobretudo no capítulo dedicado à recepção da obra de Mannheim no Brasil. Formado por artigos publicados pela autora desde 1988 e por escritos inéditos, o livro ganha unidade ao formular uma tese consistente sobre a sociologia dos anos de 1950, que tem como ponto de partida a análise de afinidades e distanciamentos que relacionam algumas das principais obras produzidas nesse contexto com Os sertões, de Euclides da Cunha, e Casa-grande E senzala, de Gilberto Freyre (neste caso, cabe destacar também a interpretação de textos menos conhecidos desse autor, mas fundamentais à compreensão de sua obra). Em seguida, a autora localiza alguns dos protagonistas mais significativos do período - Florestan Fernandes, Guerreiro Ramos e Costa Pinto -, em função das categorias de entendimento mobilizadas para compreensão da sociedade brasileira em mudança. Teriam prevalecido, nesse sentido, as perspectivas sociológicas que apostavam nas possibilidades de aplicação do conhecimento científico, que deveria orientar uma modernização brasileira focada no modelo civilizatório europeu. A parte final do livro sugere $\mathrm{O}$ enquadramento das sociologias de Evaristo de Morais Filho e Maria Isaura Pereira de Queiroz, relativamente deslocadas dessa perspectiva geral.

Esboçado o roteiro geral do livro, sigo agora com mais vagar seu argumento. O título da primeira parte - "Tempo e singularidade" - resume bem as interpretações formuladas pela autora a respeito de Euclides da Cunha e Gilberto Freyre. Ambos pretendiam elaborar uma ontologia do brasileiro, que desaguaria no "mito da ambigüidade nacional". Sobre Freyre, interessa ainda a Glaucia Villas Bôas sua concepção de tempo, que o aproximaria de Henri Bergson. Tal 
concepção seria contrária à evolucionista, permitindo ao sociólogo pernambucano apreender uma sociedade singular, cujas características centrais seriam o patriarcado, a interpenetração de etnias e culturas e o trópico.

A anallise de Social life in Brazil in the middle of the nineteenth century, tese defendida por Gilberto Freyre em Columbia (1922), deve ser destacada por remeter o leitor a um momento preparatório da elaboração de Casa grande $\varepsilon$ senzala, geralmente negligenciado. Embora não formulasse ainda, segundo a autora, a idéia de um ethos brasileiro, a centralidade conferida ao passado histórico como lastro e antídoto à uniformização imposta pela modernidade já estaria presente naquele escrito.

Diferentemente de Freyre, Euclides da $\mathrm{Cu}-$ nha simpatizava mais com a possibilidade de modernização do país, ao mesmo tempo denunciando as contradições inerentes a uma sociedade cuja formação étnica não correspondia, para o autor, aos pressupostos essenciais de uma nação moderna. Por isso, conclui a autora que para ele, não obstante a impressão positiva que teria incorporado sobre o mundo sertanejo ao presenciar o final do conflito armado em Canudos, o passado brasileiro não poderia servir de esteio às transformações vindouras. Desse modo, reconhece Glaucia Villas Bôas um "eterno dilema” como síntese do diagnóstico presente em Os sertões.

Seria, de todo modo, a valorização analítica do passado o ponto de encontro entre os autores e a marca do contexto intelectual dos primeiros quarenta anos do século XX, interessados na busca por uma "individualidade nacional". Marca essa que contrastaria com a lógica predominante da "sociologia dos anos de 1950", orientada para o futuro, apoiada numa "visão linear e evolucionista da história e em uma concepção universalista do mundo".

Os autores mais representativos dessa nova fase - discutidos na segunda parte do livro, intitulada "Imagens de futuro e tempos modernos" são Guerreiro Ramos, Florestan Fernandes e Costa Pinto. Diante da importância das obras, nada a obstar, mas a justificativa dessa escolha poderia fundamentar-se também nos embates inerentes ao campo acadêmico que mobilizaram os autores nas décadas de formação das ciências sociais em São Paulo e no Rio de Janeiro.

O terreno comum a esses três autores era o desafio de "fazer ciência e fazer história". Dessa perspectiva comum a tal "geração de mannheimianos", Glaucia Villas Bôas pontua diferenças entre os sociólogos. Guerreiro Ramos defendia uma sociologia engajada na transformação do país e, por isso mesmo, rigorosamente seletiva na incorporação de teorias estrangeiras, tendo em vista a construção de uma nação autônoma. Os sociólogos deveriam agir, nesse sentido, não apenas academicamente, mas também dentro do "quadro político-administrativo do Estado". Florestan Fernandes defendia o desenvolvimento da sociologia no Brasil como processo necessariamente vinculado à história dessa disciplina, sobretudo em sua vertente européia. Desse modo, seria possível compreender a especificidade da sociedade capitalista no Brasil e orientar as mudanças, vislumbrando a realização em nosso país de uma "ordem social competitiva". O sociólogo paulista defendia ainda uma demarcação mais rígida das posições do cientista e do político. Para Costa Pinto interessava, sobretudo, esclarecer a relação problemática dos padrões arcaico e moderno da sociedade brasileira em mudança.

Uma análise cuidadosa da recepção da obra de Mannheim no Brasil completa a segunda parte do livro, reforçando sua tese central. O grande interesse editorial por seus escritos numa época em que o desenvolvimento desse mercado era ainda incipiente - poderia ser explicado pelo fato de suas idéias justificarem a possibilidade de a sociologia constituir-se como forma de conhecimento envolvida diretamente na transformação social, entendida antes como técnica do que como saber desinteressado. Nos termos da autora: "A sociologia brasileira escolheu a 'mudança provocada', como pregava Mannheim".

Mas as coisas não costumam ser tão simples assim, e se uma sociologia do desenvolvimento prevaleceu, nem todos a teriam abraçado, pelo menos não totalmente. A terceira parte do livro "Universalismo e desigualdade" - examina, então, vozes em relativo desacordo com esse padrão. São elas as de Costa Pinto, Evaristo de Morais Filho e Maria Isaura Pereira de Queiroz. A 
presença de Costa Pinto nessa dissidência explica-se, em primeiro lugar, por seu pessimismo diante da modernização. Focando o pólo tradicional da sociedade brasileira, o autor teria explicitado o conflito inerente às transformações em curso mediante a noção de "marginalidade estrutural". O conceito indicaria a recusa pelo autor duma concepção de história evolucionista, flagrando a complexidade do mundo social e a "existência de condutas sociais orientadas por diferentes ordens sociais fundadas no convívio de diferentes temporalidades". Teria, além disso, se engajado por uma sociologia crítica, empenhada nas possibilidades de superação dos desencontros gerados na situação de mudança espontânea do mundo social.

Enfim, nos capítulos finais de seu livro Glaucia Villas Bôas trata de aspectos das obras de Evaristo de Morais Filho e Maria Isaura Pereira de Queiroz com a mesma clareza e profundidade com que analisou a "geração de mannheimianos". A consagração mais tímida de ambos teve, segundo a autora, relação com a ênfase em temas e abordagens distanciados dos padrões legitimados pela "sociologia dos anos de 1950".

A exemplo deste último argumento, a análise desenvolvida pela autora é plena de intuições interpretativas, que contribuem fortemente para o adensamento crítico das abordagens sociológicas recentes sobre o desenvolvimento das ciências sociais no Brasil.

\section{LUIZ CARLOS JACKSON é professor do Departamento de Sociologia da Faculdade de Filosofia, Letras e Ciências Humanas da Universidade de São Paulo (USP).}

\section{Senso comum e trabalbo intelectual}

Renato ORTIZ. Mundialização: saberes e crenças. São Paulo, Brasiliense, 2006. 211 páginas.

\section{Lucia Lippi Oliveira}

A melhor apresentação de Mundialização: saberes e crenças é feita pelo autor na introdução do livro. Ali ele indica suas questões e preocupações, fornecendo as razões do exame de temas específicos tratados ao longo dos capítulos. Renato Ortiz segue pontuando os significados assumidos pela globalização, ou, como ele gosta de dizer, pela mundialização. Sua questão básica pode ser assim resumida: quais são as mudanças necessárias no pensamento para que seja possível a compreensão do novo?

"Acertar o relógio" da discussão intelectual tem sido o empreendimento prioritário de Ortiz. Cultura brasileira \& identidade nacional (1985), A moderna tradição brasileira (1988), Mundialização e cultura (1994) e agora este Mundialização: saberes e crenças (2006), entre outros livros, fazem parte deste longo trajeto do autor, ocupado em discutir o processo de mudança cultural ocorrido no Brasil, ainda que em alguns textos ele esteja discutindo a Europa, os Estados Unidos, o Japão, enfim, o mundo. Tomando autores que produziram obras seminais, fazendo uso da melhor tradição sociológica, Ortiz aponta questões que passaram quase despercebidas pelo debate intelectual acadêmico, como já tinha feito ao mostrar a consolidação de uma indústria cultural nos anos de 1960 e 1970.

O autor passeia pelos clássicos da sociologia e ainda acompanha textos contemporâneos no campo do marketing e da administração, como no capítulo onde menciona a Havard Business Review como lugar privilegiado para a elaboração das crenças sobre a globalização.

No livro aqui resenhado Ortiz trata também de tema clássico, como a religião, que não é novo, mas apresenta uma nova feição no mundo globalizado e, portanto, necessita de nova compreensão. A religião deixa de ser concebida como dimensão da vida privada - agora religião e esfera 